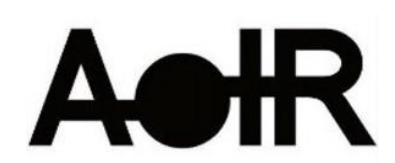

Selected Papers of \#AoIR2018:

The $19^{\text {th }}$ Annual Conference of the

Association of Internet Researchers Montréal, Canada / 10-13 October 2018

\title{
FEELING THE RHYTHMS OF CODE
}

Minna Saariketo, Aalto University

Networked digital devices and algorithmic processes of data mining have become fundamentally intertwined in people's daily lives. Conceptualizations such as softwarization (Manovich 2013), datafication (Mayer-Schönberger \& Cukier 2013; van Dijck 2014), and code/space(-time) (Kitchin \& Dodge 2011; Kitchin 2017) have offered insights into the power dynamics of code in shaping our lives, actions, and environments. Yet, only rarely has software been studied from the perspective of people's everyday experiences and meaning making practices (see e.g. Bucher 2017).

I embark from the proposition that in order to understand the sociotechnical power of software, it is not enough to analyze its technical mechanisms. The code-based infrastructures are not merely external frames or background in our daily lives, but people contribute to their production and maintenance with mundane activities and interactions (Kitchin \& Dodge 2011; Ridell 2013). Due to this mutual shaping, it is substantial to understand how people experience the everyday code-based environments and how they negotiate the places of technology in their daily lives.

In previous research, it has been noted that despite the proliferation of code-based technology, people pay little attention to the conditions of software (e.g. Kitchin \& Dodge 2011). With the concept 'technological unconscious', geographers Nigel Thrift and Shaun French (2002) capture the process in which computation has sunk as a selfevident, unseen and unknown part of the everyday. In spite of its taken-for-granted and hidden existence, code structures and times daily lives in ways that evoke feelings. In the presentation, these feelings are analyzed as cues of the power of software.

The research design is inspired by the so-called privacy mirrors (Nguyen \& Mynatt 2002). The research intervention aims at enabling reflection on the "absent presence" of software with visualisations of daily ICT use. In the autumn 2017, 13 participants (aged 27-45) used tracking software (RescueTime, ManicTime, App Usage or RealizD) in their smartphones and computers and kept a media diary for seven days. These applications tracked how often, how long, and when use occurred. The tracker provided data on such use that is otherwise difficult to record, and the media diary provided a chance to report observations and feelings as well as additional information that was not recorded by the software (e.g. who with messages were exchanged, why an app was used). In the analysis, I concentrate on the qualitative interview data as they open up a 
nuanced outlook to experiences on living in the technologically mediated world. Tracker data and media diaries were used as artefacts to initiate discussion. The semistructured interviews included questions on use of media devices, thoughts on tracked data, and the politics of platforms. The participants were invited to participate in the interpretative process by commenting on the results in the winter 2018. In previous studies, similar research design has been applied in studying how people engage with their heart-rate variability measurement data (Ruckenstein 2014) or data from their smartphones (Pybus et al. 2015).

In the analysis, I applied Henri Lefebvre's rhythmanalysis (1992/2004). Lefebvre's methodological reflections on the rhythmics of everyday life resonate prolifically with the idea of technological unconscious. The power of software actualizes in the way it structures, organizes, and imposes spatial-temporal rhythms. Both rhythms and software become commonly perceivable through disruptions or deviation (Kitchin \& Dodge 2011; Lefebvre \& Régulier 2004). Thus, rhythmanalysis is used to understand how people as users of ICTs feel the bundle of rhythms orchestrated by technology.

The concept 'rhythm' enables analysis of the manifold experiences of living in a complex technological environment, in which people as users are not straightforward in control any more than technology straightforward determines actions. Tracing how people describe feelings induced in encounters with technology from the research data leads to what moves and matters to the participants.

The analysis describes experiential landscapes of users who self-identify as having intense relationships to networked technology. The manifold experiences they depict arise from complicated intertwinements of technological and non-technological rhythms. Simultaneously, technology is perceived as an aid in organizing and managing the everyday, but it also induces feelings of losing control, chaos, and burden. The "absent presence" of software becomes visible when the fluency of daily life is disturbed: failures and abrupt moments of unavailability are a source of anguish, irritation, frustration, stress, and panic. Technology is experienced as a source of discord, when it forces practices, alters routines in unpleasant ways, or imposes temporal arrangements that are tiring, distracting, hooking, or too time-consuming.

The results diversify understandings of the power of software in everyday life. Although infrastructural conditions, such as data mining, are taken-for-granted and people submit to the terms of use offered, my analysis demonstrates that people actively negotiate their relation to devices and applications vis-à-vis the temporal organization of the everyday. This is exemplified in creating device-free zones, quitting using timeconsuming applications, switching from smartphone to "basic model", and using an app to block access to social media. A different, but equally interesting, negotiation is taking place, when a smart watch is purchased to free oneself from having to check the smart phone or when the negative feedback from one's constant smartphone use is interpreted as a result of society not being ready for the pioneer style of intense use.

Outcomes from the intervention encourage developing further research designs that use the means of softwarization itself (e.g. tracking and digital traces) to enable critical reflection. 


\section{REFERENCES}

Bucher, T. (2017) The algorithmic imaginary: exploring the ordinary affects of Facebook algorithms. Information, Communication \& Society, 20:1, 30-44.

Kitchin, M. \& Dodge, R. (2011) Code/Space. Software and everyday life. Cambridge \& London: The MIT Press.

Kitchin, R. (2017) The timescapes of smart cities. The Programmable City Working Paper 35. Pre-publication available at SocArXiv https://osf.io/preprints/socarxiv/y4e8p

Lefebvre, H. (1992/2004) Rhythmanalysis. Space, time and everyday life. London \& New York: Continuum.

Lefebvre, H. \& Régulier, C. (1985/2004) The rhythmanalytical project. In Lefebvre, H. Rhythmanalysis. Space, time and everyday life. London \& New York: Continuum, 7383.

Manovich, L. (2013) Software takes command. New York: Bloomsberg.

Mayer-Schönberger, V. \& Cukier, K. (2013) Big Data: A revolution that will transform how we live, work and think. New York: Houghton Mifflin Harcourt.

Nguyen, D. H. \& Mynatt, E. D. (2002) Privacy mirrors: understanding and shaping sociotechnical ubiquitous computing systems. Everyday Computing Lab, College of Computing and GVU Center, Georgia Institute of Technology, ftp://130.207.127.123/pub/groups/gvu/tr/2002/2002-2016.pdf.

Pybus, J. \& Coté, M. \& Blanke, T. (2015) Hacking the social life of Big Data. Big Data \& Society $1-10$.

Ridell, S. (2013) The city as a medium of media. In Tosoni, Simone and Tarantino, M. And Giaccardi, C. (eds.) Media and the City: Urbanism, Technology and Communication. Newcastle: Cambridge Scholars Publishing, 32-50.

Ruckenstein, M. (2014) Visualized and interacted life: personal analytics and engagements with data doubles. Societies 4, 68-84.

Thrift, N. \& French, S. (2002) The automatic production of space. Transactions of the Institute of British Geographers, 27:3, 309-335.

van Dijck, J. (2014) Datafication, dataism and dataveillance: Big Data between scientific paradigm and ideology. Surveillance \& Society 12:2, 197-208. 